\title{
O papel do marketing no turismo LGBT: um contributo exploratório no contexto português
}

\section{The role of marketing in LGBT tourism: an exploratory contribution in the Portuguese context}

\author{
Sónia de Sousa e Silva (SILVA, S. de S. e)* \\ Diogo de Barros Pereira Cardoso (CARDOSO, D. de B. P.) ${ }^{* *}$ \\ Bruno Barbosa Sousa (SOUSA, B. B.)
}

\begin{abstract}
RESUMO - Considerando o impacto económico no turismo e a visibilidade social crescente da comunidade LGBT no Mundo, considera-se imprescindível desenvolver o sector turístico com base na investigação e segmentação do mercado de forma a tornar um destino turístico mais competitivo. O turismo LGBT é um turismo de segmentos que tem vindo a assumir uma importância crescente no setor turístico. Neste sentido, o objetivo do presente estudo consistiu em examinar o papel do marketing turístico e qual a sua importância no que se refere às especificidades desta comunidade. Pretendeu-se, igualmente, traçar o perfil do turista LGBT, a procura e a oferta turística existente em contextos nacionais e internacionais. Foi apresentado e discutido um modelo conceptual, a testar empiricamente, por forma a melhor compreender a importância de algumas variáveis do marketing numa ótica de comportamento do consumidor do segmento LGBT. Apesar da oferta existente, este segmento, ainda está pouco explorado em Portugal no ano de 2018. No final, procede-se a uma reflexão sobre o tema com a explicitação de um modelo e discutem-se linhas de investigação futura.
\end{abstract}

Palavras-chave: Turismo; Comportamento do Consumidor; Marketing de Turismo; LGBT.

ABSTRACT - According to the economic impact on tourism and the social increase of visibility in the world of the LGBT community, it is considered essential to develop this tourism sector based on the research and the market segmentation in order to create a more competitive tourist destination. LGBT tourism is a niche tourism that has been growing in importance in the tourism sector. In this sense, the objective of the present study consists in the examination of the characteristics of this community, concretely develop the profile of the LGBT tourist, the demand and the existent tourist offer, both internationally and nationally. For that conclusion, a set of methodological research

\footnotetext{
Licenciada em Turismo (Pré-Bolonha) pelo Instituto Politécnico de Viana do Castelo (Portugal). Pós Graduação em Gestão do Turismo pelo Instituto Politécnico do Cávado e do Ave - IPCA (Portugal). Endereço físico para correspondência: Campus do IPCA, Vila Frescaínha S. Martinho. 4750-810 Barcelos (Portugal). E-mail: silva.soniap@gmail.com

** Pós Graduação em Gestão do Turismo pelo Instituto Politécnico do Cávado e do Ave - IPCA (Portugal). Endereço físico para correspondência: Campus do IPCA, Vila Frescaínha S. Martinho. 4750810 - Barcelos (Portugal). E-mail: diogobpcardoso@gmail.com

*** Licenciado em Gestão pela Universidade do Minho. Doutorado em Marketing e Estratégia (Tourism Research) pela Universidade do Minho (Portugal). Professor Universitário desde 2009 no Instituto Politécnico do Cávado e Ave (IPCA). Endereço físico para correspondência: Campus do IPCA. Vila Frescaínha S. Martinho. 4750-810 - Barcelos (Portugal). E-mail: bsousa@ipca.pt
} 
procedures was carried out: a literature review as well as a survey of tourist destinations that ensure this segmentation of the market. Despite of the existing offer, this segment is still not enough explored in Portugal. Sexuality is a sensitive subject and LGBT tourism is not always seen with good eyes, which makes difficult the communication and investigation of this market and the real impact that this segment could have in Portugal.

Key words: Tourism; Consumer behaviour; Tourism marketing; LGBT segment. 


\section{INTRODUÇÃO}

O turismo é uma atividade económica importante, podendo desempenhar um papel decisivo em termos de desenvolvimento de determinadas regiões/países. O crescimento de rendimentos, a melhoria das condições de vida das pessoas, melhores acessibilidades (redes de transporte e comunicação), o aumento do tempo de férias, estimulou o turismo como um setor de potencial contribuindo decisivamente para a prosperidade económica e social de vários países (uma força motriz da economia global). O turismo é um fenómeno que movimenta milhões de pessoas em todo o mundo (MACHADO, 2013), assumindo-se como um dos principais motores de uma economia à escala global (FERREIRA; SOUSA; GONÇALVES, 2018; MACHADO; SOUSA, 2018). Todos os anos fomenta a competição entre e dentro dos destinos turísticos" (SOUSA, 2016, p. 10). Uma "indústria" com mais de 1,1 bilhões de turistas todos os anos, com um crescimento de 4,4\% (1.135 milhões de turistas) em 2014, o turismo continua a ser uma força imparável e um dos principais impulsionadores da recuperação económica global (WORLD TOURISM ORGANIZATION, 2014, p. 2). Da necessidade de planeamento surgem novas abordagens de marketing, especificamente direcionadas para consumidores homogéneos (numa ótica de segmentação ou nichos) (SOUSA, 2010; LAGES; SOUSA; AZEVEDO, 2018).

O presente estudo consiste na análise da segmentação do Turista LGBT, um nicho de mercado que tem suscitado interesse sendo objeto de análise e estudo por diferentes perspetivas. Nesse contexto, o problema de pesquisa examinado neste artigo foi efetuar a análise dos destinos turísticos, da procura e da oferta para o turista LGBT tanto a nível em internacional como português. Para tal efeito foram levadas a cabo um conjunto de investigação metodológica, procedendo a uma revisão de literatura para fundamentação teórica do tema e objetivos envolvidos, bem com a uma pesquisa dos destinos turísticos que estavam apostando nesta segmentação de mercado. O manuscrito encontra-se dividido em três fases. Primeiramente, a revisão de literatura, designadamente as definições, terminologias e a análise do perfil do turista LGBT. Aspetos fundamentais no planeamento e desenvolvimento de um destino turístico. De seguida, tenta-se efetuar uma caraterização geral da oferta e procura deste segmento de mercado a nível internacional e por último no âmbito português. Por conseguinte, o presente estudo centra-se no contexto específico do segmento turístico LGBT, procurando analisar locais, tendências e o seu desenvolvimento, através de ferramentas 
de marketing para implementar melhorias na sua estratégia em benefício do desenvolvimento regional e local.

\section{O TURISMO LGBT}

Na presente secção, serão abordados alguns dos principais conceitos inerentes ao turismo LGBT e sua segmentação turística. O fenómeno do turismo LGBT engloba vários conceitos e especificidades que proporcionam a criação de vários subgrupos sendo analisadas algumas das terminologias mais utilizadas.

\subsection{TERMINOLOGIAS - DEFINIÇÕES E CONCEITOS}

As convenções globais organizadas pela IGLTA (International Gay \& Lesbian Travel Association) assumem um papel importante na definição de estratégias para este segmento. Aliás, foi esta associação que, em conjunto com a World Tourism Organization (UNWTO) criou um relatório global do turismo LGBT (GLOBAL REPORT ON LGBT TOURISM, 2012). Neste relatório a UNWTO afirma que os consumidores LGBT são um importante segmento de mercado no turismo reconhecidos como um grupo bastante lucrativo.

O fenómeno do turismo LGBT engloba vários conceitos e especificidades que proporcionam a criação de vários subgrupos sendo estas as terminologias mais utilizadas: Turismo Gay e Lésbico, Turismo Homossexual, Turismo Queer, Pink Tourism, Turismo LGS e o Turismo LGBT.

O turismo Gay e Lésbico consiste no turismo realizado por homens e mulheres sexualmente atraídos por indivíduos do mesmo sexo biológico. Gay e lésbica serão os termos utilizados para aludir à homossexualidade masculina e feminina, respetivamente. O turismo gay é muitas vezes utilizado como um termo unissexo (incluindo gays e lésbicas) (HUGHES; DEUCHT, 2010).

Em Portugal, o uso da expressão "homossexual", tem vindo ser gradualmente substituído pela sigla internacional LGBT. Esta alteração resulta da teoria de que o 
termo "homossexual" está fortemente ligado à medicina e de comportamentos sexuais, e o LGBT escapa a essa herança simbólica (SANTOS, 2006).

Quanto ao termo Queer, palavra inglesa usado, inicialmente, pejorativamente por quem manifestava uma opção de preferência sexual diferente, especialmente para se referir a homossexuais masculinos com gestos ou características femininas. Ao longo dos tempos, a palavra queer foi apropriada pelas comunidade lésbica-gay, reivindicando seu significado e atribuindo ao termo queer nation a ideia de uma "nação global" ou "país diverso", em que aceita positivamente a diversidade sexual (MARCIAL, 2009).

De acordo com Miskolci, R. (2009) a teoria queer emergiu em oposição crítica aos estudos sociológicos sobre minorias sexuais e gênero. $\mathrm{Na}$ mesma linha de pensamento, Santos (2006, p. 7) afirma que esta surge da insatisfação quanto à literatura existente sobre "sexualidades dissidentes" centrada em categorias rígidas. Esta propõe a desestabilização, subversão e emancipação dos fenómenos relacionados com sexualidade e o género, não mais entendidos de forma linear e regular, mas antes instáveis, fluidos, tão reais quanto imaginados, e sempre politizados.

Giffney (2004) afirma que contrariamente ao que por vezes é veiculado, queer não é sinónimo de gays e lésbicas. A teoria do queer defende que a sexualidade não pode simplesmente ser entendida através das categorias "homossexuais" e "heterossexuais", uma vez que as identidades, desejos e categorias sexuais são fluidos e dinâmicos e a sexualidade está, inevitavelmente, ligada de relações de poder (GAMSON; MOON, 2004).

Nas palavras de Seidman (1996, p. 13), o queer é o estudo "daqueles conhecimentos e daquelas práticas sociais que organizam a 'sociedade' como um todo, sexualizando heterossexualizando ou homossexualizando - corpos, desejos atos, identidades, relações sociais, conhecimentos, cultura e instituições sociais" (MISKOLCI, R., 2009, p. 154). A teoria queer "consiste em tornar visível, criticar e distinguir o normal (estatisticamente determinado) do normativo (moralmente determinado)" (GIFFNEY, $2004^{1}$ citado em: SANTOS, 2006, p. 6).

Para Touraine (2005) a proposta Queer consiste na ausência de separação global entre homens e mulheres representando a sexualidade de cada indivíduo como um

\footnotetext{
T GIFFNEY, N. (2004). Denormatizing queer theory: More than (simply) lesbian and gay studies. Feminist Theory, 5 (1), p. 73-78.
} 
conjunto de fragmentos de sexualidades diversas que todos os atores vivem segundo as circunstâncias e os seus parceiros.

Assim, o Turismo Queer refere-se a todas as expressões de identidade de género e orientações sexuais que não sejam a heterossexualidade e a bissexualidade.

O Pink Tourism - em português Turismo Rosa, é utilizado normalmente em referência ao pink market (mercado rosa) ou ao pink dollar/pink pound (dinheiro rosa), termos que representam o mercado gay e lésbico, e o poder de compra deste grupo, respetivamente (PRITCHARD et al., 2000). O símbolo "triângulo rosa invertido", é o emblema da comunidade homossexual, símbolo da opressão a que a comunidade era exposta. Símbolo de identidade que procura lembrar o tremendo genocídio do nacionalsocialismo Alemão, depois de ser uma forma de marcar homossexuais masculinos em campos de concentração Nazistas. Outro emblema de identidade é o arco íris como símbolo de diversidade sexual e sua possibilidade de existência inclusiva (MARCIAL, 2009).

O segmento LGBT, inicialmente conhecido como GLS (Gays, Lésbicas e os simpatizantes) mas que, posteriormente, incorporou o público transexual, travesti e bissexual sendo definido como LGBT o turismo que consiste nos produtos e serviços turísticos realizados por e para as lésbicas, gays, bissexuais e transsexuais (GLOBAL REPORT ON LGBT TOURISM DA UNWTO - UNITED NATIONS WORLD TOURISM ORGANIZATION, 2012). Quanto ao LGS, (gays, lésbicas e os simpatizantes) o "S" serviria para incluir os "simpatizantes", sujeitos não-LGBTS, porém, frequentadores de bares e boates destinados, via de regra, ao público LGBT (FACCHINI, 2005). Atualmente, fala-se de uma versão mais completa da sigla do movimento, o LGBTPQIA+ (L: Lésbicas; G: Gays; B: Bissexuais; T: Travestis, Transexuais e transgêneros; P: Pansexuais; Q: Queer; I: Intersex; A: Assexuais; + (pessoas que não se sintam representadas por nenhuma das referidas). (DUARTE, 2017).

\subsection{PERFIL DO TURISTA LGBT}

O comportamento dos turistas LGBT é o centro de muitas convenções globais que são realizadas todos os anos para debater temáticas referentes a este segmento. 
Segundo o Global Report on LGBT Tourism (2012) houve um aumento da visibilidade da comunidade e da discussão do seu impacto económico no turismo, na medida em que é identificado como um nicho de mercado altamente lucrativo.

Todavia, o mercado LGBT é um segmento difícil de medir. Existem poucas estatísticas sobre essa orientação sexual (PRITCHARD et al., 1998).

A inexistência de estatísticas exatas não anula, de qualquer maneira, um verdadeiro impacto do turismo LGBT na economia global e nacional. Pritchard et al. (1998) afirmam que este mercado está em constante crescimento como resultado de uma maior permissividade social. No ano de 2011 a comunidade LGBT representou [em 2011] 35 milhões das chegadas e aproximadamente 36 milhões de pernoitas nos destinos internacionais em todo o mundo. Estima-se que o turismo gay represente $10 \%$ do fluxo mundial anual de viajantes e $15 \%$ da faturação das empresas do sector (UNWTO, 2012).

De acordo com o Global Report on LGBT Tourism, publicado pela UNWTO em 2012, o turista LGBT é reconhecido como um sujeito que viaja com bastante frequência, demonstra uma aptidão para o consumo acima da média e que são turistas extremamente diversificados.

Por conseguinte, World Tourism Organization (2012) sublinha que é importante observar que a experiência do turista LGBT, como os viajantes em geral, pode variar segundo o género, raça, rendimento, classe social, idade etc. Para Tebje (2006) o mercado LGBT pode ser caraterizado segundo dois grupos: as pessoas, dos 18 e 30 anos, focadas na diversão e em destinos homossexuais e os turistas de faixas etárias superiores aos 35 anos que procuram destinos não evidenciados como LGBT. Realçando ainda, que, no geral, o turista LGBT tem rendimentos superiores à média, menos responsabilidades familiares e que viajam com maior frequência em comparação com os segmentos tradicionais (TEBJE, 2006).

Na mesma linha de pensamento, Altaf e Troccoli (2009), sublinham que este mercado representa um contingente relevante, com alto poder de compra e um nível cultural acima da média, portanto, um importante segmento de consumo. Holcomb e Luongo (1996) afirmam que casais homossexuais têm rendimentos médios mais elevados do que os casais heterossexuais. Além disso, menos de 5\% dos casais homossexuais têm filhos, e por esse motivo têm mais tempo e dinheiro para viajar. 
Otero, Alén e Domínguez (2014) afirmam, no entanto, que é um mercado fiel à marca, principalmente no que se refere às empresas turísticas, em particular as unidades de alojamento, e destinos "gay friendly".

O Instituto de Pesquisas e Estudos do Turismo do Rio Janeiro, órgão da Associação dos Embaixadores de Turismo do RJ e a Fundação Cesgranrio (2017) fez um estudo aos turistas LGBT no Rio de Janeiro, caracterizando este segmento por ser constituído, maioritariamente, por pessoas do sexo masculino, provenientes da Europa, com idades compreendidas entre 28 a 45 anos. O grau académico é superior e, em média, permanecem no destino entre 4 a 7 dias, em hotéis com um consumo médio/dia de 90 a 150 USD. Os chamados DINK (Dual Income, No Kids - Rendimento Duplo, Sem filhos), termo utilizado regularmente para caracterizar o perfil de gays e lésbicas com rendimentos superiores e que gastam mais do que a média em viagens, entretenimento e moda. (WORLD TOURISM ORGANIZATION, 2012).

O segmento de turistas LGBT pode ser considerado "sazonadores turísticos" (OTERO; ALÉN; DOMÍNGUEZ, 2014). Porque, por um lado, não realizam férias nas épocas altas e as suas viagens não dependem dos ritmos sociais impostos (status de DINK), o que permite não só um maior número de viagens, mas também, uma maior liberdade na escolha do período de férias. Por outro lado, muitos LGBT preferem viajar para destinos turísticos alternativos para fugir à abundância das famílias tradicionais e ter uma maior "liberdade".

Quanto às suas necessidades e motivações, os turistas viajam por uma multiplicidade de razões e os consumidores LGBT não são exceção. Segundo Ro, Choi e Olson (2013) as suas motivações podem ser bastante diferentes de outros segmentos de mercado, nomeadamente as famílias tradicionais, viajantes individuais e outros grupos minoritários. Clift e Forrest (1999) apontam as motivações principais como sendo a necessidade de fuga à rotina, conforto, boa comida, descanso, sol e boa vida noturna. Para além disso, o facto de escolherem um destino conhecido como "gay friendly" pode servir como afirmação da sua identidade enquanto homossexuais (HUGHES, 1997; PORIA; TAYLOR, 2002; LUCENA et al., 2015).

Segundo Pritchard et al. (2000) estes escolhem destinos "gay friendly", devido à necessidade de segurança e conforto num meio constituído por pessoas de mentalidade semelhante. Como o turismo representa a oportunidade de "fugir de tudo", de acordo 
com os autores, de facto o desejo da fuga da pressão de ser homossexual no mundo predominantemente heterossexual é, sem dúvida, uma das principais motivações na escolha de um destino. Sanches, Mancini e Nascimento (2010) sublinham que o turista LGBT procura destinos ou eventos onde possam sociabilizar com seus semelhantes, divertir-se sem ressalvas quanto à sua orientação sexual, e eventualmente formar pares. A grande maioria considera importante o requisito "gay friendly" na escolha de um destino e ou produto (BEREZAN et al. 2015). Ao nível da escolha do destino, de acordo com Hughes e Deutsch (2010) os principais fatores são, primeiramente o conforto e o relaxamento. A segurança, o preço e as acessibilidades como as exigências do público LGBT (SANCHES; MANCINI; NASCIMENTO (2010).

Quanto ao tipo de turismo para além do turismo Sol e Mar, a maioria procura o conhecimento, aprendizagem e a relação com outras culturas (SANCHES; MANCINI; NASCIMENTO, 2010). Segundo Korflür, Vela e Molina (2007) tradicionalmente o turista LGBT procura os destinos de sol e mar e as grandes cidades (city-breaks). Ambos os destinos têm em comum uma ampla oferta de estabelecimentos dirigidos a este segmento de mercado.

Paralelamente, uma cultura gay friendly, com eventos e comunidade gays e uma oferta direcionada a este público são também, fatores importantes na escolha do destino (HUGHES; DEUTSCH, 2010). Por conseguinte, pode-se afirmar que a sexualidade influencia definitivamente as suas escolhas. Para um grupo que sofreu e continua a sofrer repressão em muitas partes do mundo, elementos como a não discriminação em relação ao sexo, é importante no momento da escolha de destinos (WORLD TOURISM ORGANIZATION, 2012).

Os turistas gays escolhem destinos onde o espaço heterossexual não imponha restrições (PRITCHARD et al., 2000), a maioria viaja com o propósito de socializar com outros indivíduos homossexuais, ter acesso ao gay space, ou pelo menos evitar a homofobia (MONTERRUBIO 2008, p. 158). Para Monterrubio 2008, a tolerância e a aceitação da homossexualidade podem ser suficientes, no entanto a existência do gay space é essencial. O turista gosta de demonstrar, livremente o seu afeto e dar as mãos em público (KIRBY, 1997). Para um grupo que sofreu e continua a sofrer repressão em muitas partes do mundo, elementos como a não discriminação em relação ao sexo, é 
importante no momento da escolha de destinos (WORLD TOURISM ORGANIZATION, 2012).

Todavia, tal como os turistas mainstream, os turistas LGBT procuram férias diferenciadas. Existem os turistas que procuram convívio social em círculos gays (maioria das faixas etárias mais jovens) e turistas que procuram conhecer outras culturas (destinos pela sua oferta cultural), independentemente de serem conhecidos como destinos gays ou não (BEREZAN et al., 2015). Atualmente, este segmento cada vez mais exigente, impulsionou o surgimento dos operadores turísticos especializados neste mercado. Estes tendem a disponibilizar serviços personalizados um pouco por todo mundo, em locais seguros e tolerantes e construindo parcerias com as próprias comunidades locais. A IGLTA possui muitas dessas organizações entre os seus membros, bem como destinos que procuram compreender melhor as características do mercado LGBT e pretendem apoiar as empresas locais para a captação deste mercado (WORLD TOURISM ORGANIZATION, 2012) e comunidades locais (NITSCHE, 2013).

\section{OFERTA TURÍSTICA A NÍVEL INTERNACIONAL}

O espaço físico ou a localização espacial exercem um papel essencial na criação da identidade e, em particular, na formação da identidade sexual. Alguns autores consid

Movimento Homossexual, na década de 70. Na comemoração dos 40 anos da revolta de Stonewall, vários stakeholders e dirigentes da cidade de Nova York anunciaram uma nova campanha de marketing com o slogan "Rainbow Pilgrimage" com o intuito de que a cidade de NY fosse representada através do acontecimento e se tornasse um ritual de passagem para os turistas LGBT.

É difícil calcular o número exato de visitantes LBGT por ano na cidade de Nova York, mas estima-se que devam ser mais de 7 milhões. O seu impacto económico representa mais de 7 mil milhões de dólares por ano para os negócios e as organizações da cidade, o que mostra que o segmento é de facto um bom negócio (WORLD TOURISM ORGANIZATION - GLOBAL REPORT ON LGBT TOURISM, 2012). Há 
pouco mais de duas décadas, o mercado gay ainda se encontrava underground e foi há 30 anos que alguns pioneiros como Hanns Ebensten começaram a oferecer tours a homens gays. Antes da criação da International Gay Travel Association (IGTA), havia poucos destinos gays. Com a criação de operadores turísticos como RSVP, Atlantis e Olivia, especializados no mercado de gays e lésbicas, surge um marco no desenvolvimento da indústria e no turismo gays e lésbicas (BEREZAN et al., 2015).

Foi nos anos 90 que a Wall Street Journal reconheceu a comunidade LGBT como o "dream market" (KAUHANEN, 2015). Com o contínuo desenvolvimento do movimento dos direitos dos homossexuais, o pink money passou de uma pequena percentagem de mercado para uma "indústria" em crescimento exponencial na generalidade do mundo.

O valor do público LGBT para o turismo tem sido cada vez mais discutido, sendo impossível negar que seja um segmento que contribui cada vez mais para o sector.

No entant

desde a sua imagem até às infraestruturas turísticas, passando, principalmente, pelas atitudes da comunidade local em relação ao turismo e aos turistas homossexuais. Apesar da aceitação geral, vários estudos revelaram que os bairros, bares e outros locais LGBT nos Estados Unidos da América e na Europa estão a diminuir à medida que a necessidade social de espaços seguros para as populações gays diminui. Esta evolução também significou um alargamento das variáveis culturais, sociais, pessoais e psicológicas dos viajantes LGBT, a forma como eles interagem uns com os outros e, mais importante, com o mundo. (WORLD TOURISM ORGANIZATION, 2012). Embora a literatura defenda a globalização do turismo LGBT e a "desestigmatização" de certos destinos turísticos (OSWIN, 2006), tradicionalmente a comunidade LGBT opta por destinos de sol e praia e pelos fins de semana nas grandes cidades (city-breaks). Não há estatísticas oficiais que consigam dar uma ideia precisa da dimensão atual apresentada por estes dois tipos de destinos no turismo homossexual. Ambos os destinos têm em comum uma ampla oferta de estabelecimentos destinados ao público LGBT. Segundo o relatório global sobre o turismo LGBT além do impacto económico 
observado também a aprovação da legislação a favor da igualdade de matrimónio para casais do mesmo sexo influenciou de uma forma muito positiva a imagem de tolerância, respeito e progresso no destino aumentando desta forma o turismo desse segmento no mundo (WORLD TOURISM ORGANIZATION, 2012). A Turespaña (Organização Nacional de Turismo Espanhol) afirmou que o facto de, em 2005, o país introduzir na lei o direito de casamento de pessoas do mesmo sexo, favoreceu e alterou positivamente a imagem de Espanha como um destino LGBT. Foi, a partir desta declaração, que vários destinos turisticos decidiram promover o seu destino como um ótimo destino para a comunidade se casar, destinos de lua de mel, ou "gayfriendly". A exemplificar, a campanha "Says I Do" da Irlanda e a companha "Love Is Great" da VisitBritain (WORLD TOURISM ORGANIZATION, 2012).

\subsection{OS DESTINOS TURÍSTICOS}

O conceito de destino gay surgiu, inicialmente, na América do Norte e na Europa, fundamentalmente em destinos de sol e mar e grandes cidades como, Provincetown, Massachusetts, Fire Island, NY, nos Estados Unidos da América ou Sitges, em Espanha e Mykonos, na Grécia. Estas foram algumas das cidades de férias sazonalmente sobrelotadas com uma base na procura em grande parte gay.

No entanto, o turismo LGBT passou a ser mais visível em todo o mundo. De acordo com a tendência global e graças à maior aceitação e respeito pela comunidade LGBT, assim como à Internet e ao surgimento de empresas turísticas gayfriendly e/ou especializadas neste mercado, os viajantes LGBT tornaram-se mais ambiciosos e aventureiros nos seus planos de viagem (BEREZAN et al., 2015). Esses fatores obrigaram uma mudança considerável no conceito de turismo LGBT.

Os viajantes LGBT e suas famílias passaram a selecionar os destinos segundo vários fatores, uma vez que a população LGBT é tão diversificada e fragmentada quão a população em geral. Todavia, as expressões são muitas vezes particularmente extremas entre os sexos, pois os gays e lésbicas frequentemente partilham alguns dos mesmos hábitos de viagem. Por exemplo, um estudo realizado em 2015 pela Community Marketing, Inc. descobriu que $66 \%$ dos homens homossexuais foram para um bar gay e $60 \%$ para um bairro gay durante as suas férias nos últimos 12 meses. Quanto ao 
mercado lésbico apenas $39 \%$ das mulheres lésbicas frequentaram um bar gay ou um bairro gay durante as férias. Nota-se que as atividades resultantes na variável de género ainda são importantes para os viajantes masculinos homossexuais. Paralelamente, são mais propensos a viajar exclusivamente com adultos, possivelmente como resultado de ter menos filhos, mais tempo e um orçamento maior, permitindo uma maior flexibilidade de viagem. Por outro lado, o estudo revelou que as mulheres lésbicas estavam mais inclinadas para férias com famílias, viagem e restrições orçamentais mais alinhadas com o mercado tradicional (WORLD TOURISM ORGANIZATION GLOBAL REPORT ON LGBT TOURISM, 2012).

Embora a segurança continue a ser uma preocupação para os viajantes LGBT, esta deixou de ser um fator que os restringe na visita dos destinos (BEREZAN et al., 2015). Existem por todo o mundo cidades com uma forte comunidade gay ou recetividade da mesma. Sobre os destinos "gay-friendly" a nível mundial, constata-se que entre os destinos europeus que se destacam na preferência da comunidade gay para as suas férias, encontram-se as ilhas gregas, além de Lesbos e Mikonos, conhecidas há anos pelo seu ambiente 'gay friendly', existindo muitas outras ilhas cada vez mais despertas para este público. Um outro destino de referência na Europa é Berlim, Alemanha. A cidade é bastante desenvolvida no que diz respeito ao turismo e às férias LGBT. Existe uma série de bares e clubes gays e é nesta cidade que funciona o Instituto de Sexologia e Medicina Sexual que luta contra a discriminação sexual. Esta cidade destaca-se também por ter a terceira maior comunidade gay da Europa o que torna o destino moderno e apetecível para o mercado LGBT (BEREZAN et al., 2015).

Em Espanha, destino de referência do mercado LGBT se oferece na sua totalidade 1250 locais e estabelecimentos específicos "gayfriendly", assim como várias agências especializadas. Este segmento de mercado gera 3,3 mil milhões de Euros por ano só neste destino em particular (HAUSER, 2005). No que concerne aos Estados Unidos da América, desde os anos 60 que Palm Springs e São Francisco na Califórnia, Flórida, Key West, Miami e Fort Lauderdale atraem a comunidade LGBT.

$\mathrm{Na}$ Argentina, a cidade de Buenos Aires é considerada um dos principais destinos turísticos LGBT. De acordo com o colóquio "Simpósio Internacional de Turismo Gay e Lésbico 2005", em 2004, Buenos Aires recebeu 5,25 milhões de turistas, mais $38 \%$ do que no ano anterior. Segundo a Secretaria de Turismo da cidade, a capital 
passou a ser considerada o destino mais procurado pelo turismo Gay, devendo-se especialmente à postura -gay do governo que apoia, suporta e publicita vários eventos para a comunidade, praias exclusivas e vários estabelecimentos e locais "Gay Friendly".

O México é por sua vez também bastante procurado, especialmente nas cidades de Acapulco e Puerto Vallarta que se destacam pelas infraestruturas e hotéis voltados para o segmento (BEREZAN et al., 2015).

cidade

São vários os destinos que atraem, por si só, os turistas LGBT. Todavia, os eventos direcionados ao mercado LGBT são considerados um factor importante na atração do destino. Apreendendo o caso do Brasil, onde existe um calendário com vários eventos anuais como o Carnaval ou "O Dia do Orgulho Gay”. A nível Europeu, pode-se destacar: LGBT Paris, LGBT Madrid, LGBT Londres, LGBT Amesterdão, e o LGBT Copenhaga (RODRIGUES et al., 2018).

As festas e festivais, importantes por o seu papel cultural e social, vêm-se revelando como promotoras do turismo, animando cidades e os seus atrativos (ANDERSSON; GETZ, 2008). Tratam-se de estratégias de marketing turístico, que promovem produtos e serviços, projetam a imagem dos destinos, contribuem para o fortalecimento da identidade e o desenvolvimento socioeconómico do destino.

\section{LGBT EM PORTUGAL}

Em Portugal, foram vários os fatores que impediram a formação de enclaves gays e lésbicos que permitissem construir um sentido de identidade comum na comunidade. Só a partir da década de 90 começam a surgir vozes mais consistentes e duradouras no associativismo gay e lésbico português, e as primeiras publicações assíduas - como revistas e jornais. Essa evolução regista-se apenas nas cidades mais desenvolvidas como Lisboa, Porto e a região do Algarve.

A primeira organização de orgulho LGBT fundou-se em 1992 e em 1995, surge uma das associações mais ativas no panorama LGBT nacional - ILGA-Portugal, 
passando, em 1997, a ter a sede e onde foi criado o Centro Comunitário Gay e Lésbico de Lisboa que agora chama-se Centro LGBT. Trata-se de um centro de documentação, com a recolha e manutenção de informações LGBT de Portugal. Também, foi em 1997 organizado o primeiro Festival do Orgulho LGBT, o primeiro Festival de cinema Gay em Portugal assim como a abertura do centro LGBT, em Lisboa (RODRIGUES et al., 2018).

Portugal passou a ser uma referência na conquista dos direitos, tais como adoção por parte de casais homossexuais, lutas contra a discriminação e no que se refere ao casamento entre pessoas do mesmo sexo. Através do Rainbow Map (ILGA- EUROPE, 2016b) é possível analisar o clima social para a comunidade LGBT, de acordo com a situação dos direitos humanos, dos 49 países da Europa. No Rainbow Map de 2016, Portugal fica em $6^{\circ}$ lugar no ranking, tendo este por base as categorias: igualdade e não discriminação; família; crimes de ódio e discursos de ódio; reconhecimento legal do género; liberdade de expressão; e asilo.

No que concerne à "indústria” do turismo, o segmento LGBT em Portugal, é um mercado em crescimento, principalmente em Lisboa, onde a oferta de roteiros gay é cada vez maior, tal como destaca a comunicação social a nível mundial. No entanto, o Turismo de Portugal I.P. e a Associação de Turismo de Lisboa não têm dados que o comprovem.

Por outro lado, as associações LGBT também não têm noção do crescimento, uma porque não trabalham de forma consistente no turismo. No entanto, constatam uma maior procura do mercado devido ao grande número de turistas LGBT que procuram estas associações para a pesquisa de informação turística. Criar uma comunicação e um marketing específico para este mercado é uma das lutas que as organizações direcionadas para este nicho, estão a tentar travar com o Turismo de Portugal I.P. até porque o turismo LGBT não integra os mercados-alvo do turismo português, daí os números alcançados serem adquiridos através de deduções baseadas em dados demográficos existentes da população LGBT.

No que se refere a participação de entidades públicas em assuntos da comunidade LGBT, Lisboa parece ser o único caso em que se encontra uma ligação consistente entre a Câmara Municipal e o trabalho desenvolvido pelas organizações LGBT. A Câmara Municipal de Lisboa é patrocinadora, do Festival de Cinema Gay e 
Lésbico de Lisboa e colaboradora do Arraial Pride, eventos que apelam ao turismo gay na cidade. No ranking do Spartacus World, que edita vários guias internacionais de turismo gay, Portugal foi considerado o $16^{\circ}$ melhor destino gay do mundo.

\subsection{A OFERTA TURÍSTICA LGBT}

Primeiramente, considera-se importante referir, alguma das principais agências a trabalhar com o turismo LGBT.

A Saga Escape pertencente ao departamento de turismo para a comunidade LGBT da Saga Travel Portugal, membro associado da IGLTA - International Gay and Lesbian Travel Association é uma agência de viagens destinada à comunidade gay e lésbica em Portugal. Organiza viagens e estadas por todo o mundo: prides, festas, cruzeiros, roteiros de inverno, verão ou mesmo pacotes direcionados ou concebidos para gays.

A Be Out, criada pelo grupo Geowinds nasceu em 2011 como resposta a um mercado cada vez mais emergente: o do turismo LGBT (RODRIGUES et al., 2018). Esta agência sentiu a necessidade de criar um produto específico para responder a uma procura que aumenta de dia para dia. Tornar Portugal num destino de eleição para a comunidade LGBT é o propósito assumido pela Be Out. Esta agência trabalha em parceria com a IGLTA (Associação Internacional de Turismo Gay e Lésbico) e a IGLTA Nacional. A Be Out regista que os padrões de procura são hotéis de quatro e cinco estrelas, aventuras com programação cultural, vontade de passear pela cidade e viver a movida noturna da cidade.

La Demence, agência especializada no turismo LGBT com sede em Bruxelas responsável por uma das maiores festas gay europeias, organizou pela primeira vez em 2017, um cruzeiro que saiu do Porto de Lisboa exclusivamente para gays. Esta escolha pode ser explicada pelo interesse turístico que a capital portuguesa tem assumido nos últimos anos. Lisboa é a quinta cidade europeia com o crescimento mais rápido em número de visitantes internacionais, segundo um estudo do "Global Cities Index 2016". Segundo dados provisórios do INE de 2017, Lisboa registou no ano de 2016 cerca de 12 milhões de dormidas e 5 milhões de hóspedes. A grande maioria dos mais de dois mil participantes neste cruzeiro chegaram mais cedo a Lisboa para conhecer a cidade. Este 
cruzeiro tem, também, passagem pelo arquipélago da Madeira, outro destino emergente junto das comunidades LGBT. Em 2017 foi organizado a primeira marcha do orgulho gay neste arquipélago, que começa a ter um ambiente misto e muito acolhedor no que respeita à comunidade LGBT (RODRIGUES et al., 2018).

O preço da viagem rondava os 1000 euros por pessoa, com diferentes serviços à disposição, como por exemplo, duas festas temáticas por dia, excursões diurnas nos locais onde o navio acostar, tratamentos de beleza e spa. Foram oito dias com paragens e excursões opcionais na ilha da Madeira, La Palma, Gomera, Tenerife e Lanzarote.

Reportando-se à cidade portuguesa com mais oferta para este nicho, destacam-se alguns exemplos de atividades gay friendly divulgadas no Gay Lisbon Guide já disponível em papel e online (RODRIGUES et al., 2018). Estes guias são distribuídos nos pontos turísticos, monumentos, bares, discotecas e lojas de Lisboa ao longo do ano, assim como nos principais eventos LGBT da capital. As versões online destes guias estão customizadas para smartphones, tablets e computadores. O Gay Lisbon Guide contempla walking tours para explorar a história e o estilo de vida de Lisboa em ambientes LGBT; eventos e festas; tours personalizadas; viagens de um dia até à Praia 19 na Costa da Caparica, Sintra e Cascais; fado night tour (locais gay friendly), Gay Lisbon by night tour - descoberta do lado gay de Lisboa (bares, discotecas, saunas e lugares para fazer compras). Este guia está contemplado no Lisbon Gay Circuit plataforma online dedicada a oferta gay em Lisboa. Oferece informações sobre as ofertas gay friendly no destino, nomeadamente, bares, discotecas, festas, restaurantes, saunas, alojamentos, centros comerciais e tours especializados, tais como o Lisbon Beach Tour e o Lisbon Gay Tour (RODRIGUES et al., 2018).

Segundo João Paulo, editor do portal "Portugal Gay” Lisboa é uma cidade com um maior número de infraestruturas gays e mais consolidada enquanto destino gay europeu que a cidade do Porto. Sublinha que, deve-se, principalmente, ao facto de a capital ser constituída por migrantes, o que facilita uma atmosfera cosmopolita, enquanto no Porto a população é mais constituída por famílias. No entanto, João Paulo acredita que a "eleição da cidade como melhor destino turístico da Europa tenha feito aumentar o fluxo de visitantes LGBT e a tolerância da comunidade face a esta procura”.

Lisboa está na moda e é o destino com mais procura e oferta LGBT em Portugal (RODRIGUES et al., 2018). Na praça do Príncipe Real localizam-se os grandes pontos 
de encontro gay onde se poderá circular livremente pelos bares e locais gay-friendly. Há hotéis, nas cidades de Porto e Lisboa, que só aceitam hóspedes gays, outros que aceitam todos os turistas e garantem que os visitantes homossexuais se sentirão bem-recebidos. Lisboa assistiu também a uma explosão de pequenas residências para o segmento. Por outro lado, há praias frequentadas pelo público gay, inclusive praias de nudismo. É o caso da Praia 19 na Costa da Caparica (considerada pela Gay Star News uma das 11 melhores do mundo para o turismo LGBT).

A movida noturna é um ponto muito importante na escolha do destino de férias para muitos turistas LGBT. Lisboa tem-se beneficiado com isso, pois cada vez tem uma oferta mais diversificada e sustentada com festas LGBT, com destaque especial para a festa do Conga realizada todos os meses em diferentes locais da cidade.

Lisboa começa também a acolher festas de Dj's de renome no circuito gay internacional, como "We Party", "Salvage", "Papa Party". Em Lisboa, a zona do Príncipe Real é conhecida como um "Bairro Gay", e lá se concentram a maioria dos bares LGBT, entre eles "Woof LX", "Bar 28", "Trumps", "Woof X”, "Bar CRU”, "The Cock". Outra zona é a "esquina-gay" no Bairro Alto, que alberga também vários Bares LGBT. No Porto a festa é menor e não existem zonas LGBT, embora tenham alguns bares, como é o caso do café Lusitano e o Conceição 35 na baixa da cidade, o Paços Manuel e o Zoom em Santa Catarina e o Café Au Lait nas galerias. No Algarve existe uma grande oferta, contudo bastante sazonal. Destaque para alguns bares como o "Connection Club", "Gayvota Club", "Next Bar", "Arco Bar", "Boémio Bar”, onde há por vezes a presença de DJ's, música ao vivo e espetáculos de "gogo boys e bailarinos" (HOFFMANN et al., 2018).

Em Portugal, existem eventos muito diversificados ao longo do ano, entre eles: o "Porto Drag Festival", "Prémios Arco-Íris" no Mercado Time Out, Encontro Nacional de Jovens Trans organizado pela rede ex aequo, Ciclo de Cinema LGBT, Marcha pelos Direitos LGBT em Braga, Arraial Pride, Hot Season Festival, Acampamentos de Verão para Jovens LGBTI. O LGBT Lisboa é organizado pela ILGA Portugal no Terreiro do Paço e tem como lema “Adeus Santo António! Olá festas do Orgulho”. 


\section{MODELO CONCEPTUAL PROPOSTO}

Face ao exposto, o presente estudo tem como objetivo compreender a importância de algumas variáveis do marketing numa ótica de comportamento do consumidor do segmento LGBT (FIGURA 1).

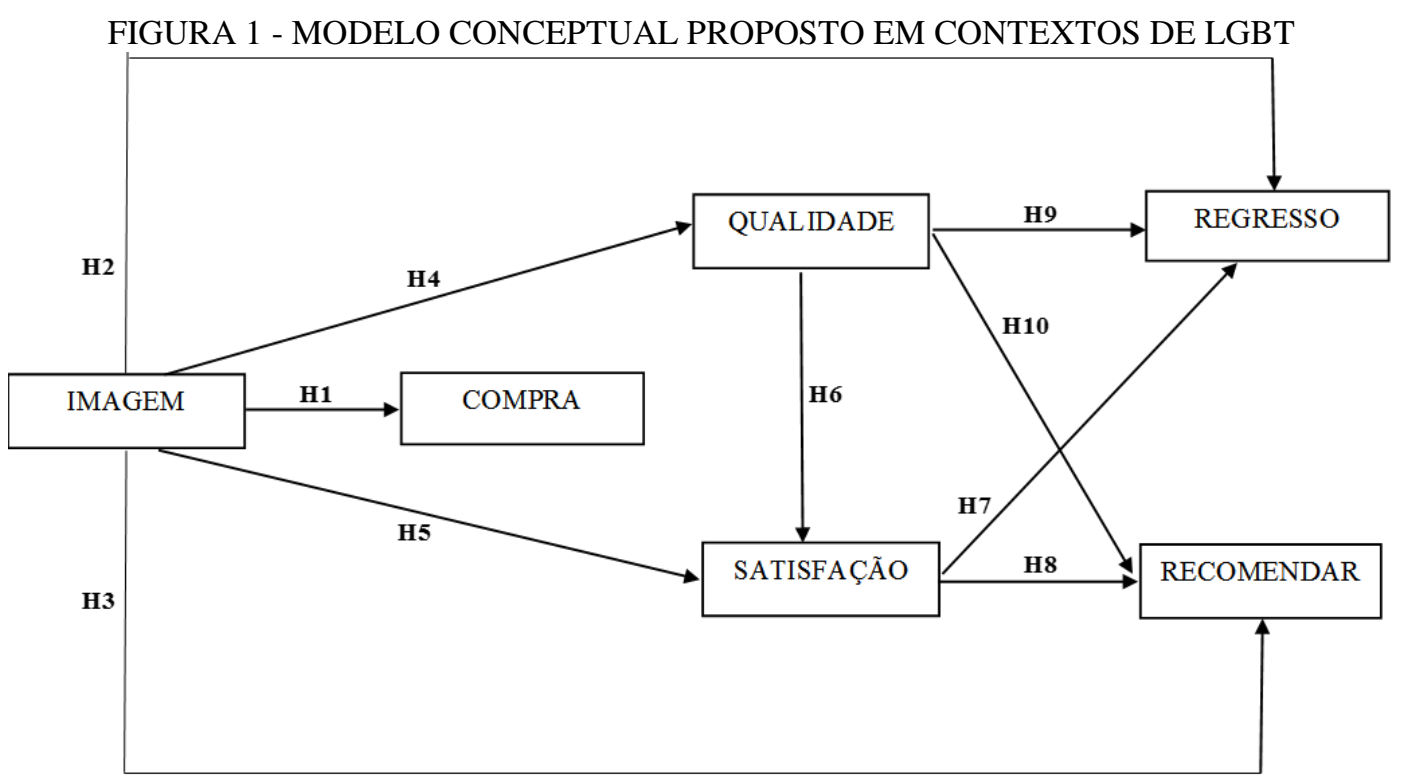

FONTE: Adaptado de Bigné et al. (2001).

O modelo proposto está adaptado a partir do contributo de Bigné et al. (2001), expõe a relação entre diferentes dimensões, tendo por base um conjunto de hipóteses (H). Os autores pretendem com este modelo compreender o papel da imagem no comportamento consumidor (e.g. LGBT), estabelecendo, assim, cinco variáveis: imagem, qualidade, satisfação, regresso e recomendar. No entanto, este estudo pretende estudar o papel da imagem durante todo o processo de compra do cliente. Em contextos específicos de marketing turístico, como disso seja exemplo o segmento LGBT, há ainda bastante caminho a percorrer no estudo das relações causais entre a imagem e as intenções comportamentais por parte do consumidor. Neste estudo desenvolveu-se um modelo teórico derivado da literatura apresentada. A teoria permitiu estabelecer as relações entre constructos. A componente empírica exploratória do trabalho permitiu ajustar o modelo ao contexto do marketing de turismo, sendo que os próximos passos implicam testar empiricamente (i.e. administração de inquéritos por questionário) o modelo conceptual proposto no mercado português. 


\section{CONSIDERAÇÕES FINAIS E PRÓXIMOS PASSOS DE INVESTIGAÇÃo}

O mercado LGBT é um mercado que cresceu e continua a crescer ao longo dos anos. A pesquisa realizada mostrou que os efeitos são sempre positivos para os prestadores de turismo, tendo em conta que o turismo LGBT cresce à medida que a condescendência se difunde pelo mundo, é economicamente, eticamente e sociopoliticamente benéfico para um destino atrair este segmento de mercado.

No entanto, o turismo LGBT também acarreta alguns efeitos negativos provenientes do antagonismo, problemas de discriminação e falta de sensibilidade, podendo ter consequências desfavoráveis para o destino turístico. É importante que os destinos turísticos e os vários stakeholders criem condições de tolerância e respeito pelo individuo. Por conseguinte, torna-se imprescindível apostar no desenvolvimento sustentável do destino numa era em que a reputação e recomendações têm um enorme peso no que toca à escolha do destino.

No contexto português, o segmento LGBT, ainda não obteve uma exploração devida. Contudo, as várias organizações direcionadas para este nicho têm lutado na criação de uma comunicação e um marketing específico para este mercado, até porque o turista LGBT não integra os mercados-alvo do Turismo de Portugal I.P. O mercado LGBT é um segmento, muitas vezes, difícil de quantificar e estimar.

Por conseguinte, o modelo conceptual proposto pretende compreender a importância de algumas variáveis do marketing numa ótica de comportamento do consumidor do segmento LGBT. O modelo proposto e adaptado a partir do contributo de Bigné et al. (2001), expõe a relação entre diferentes dimensões, tendo por base um conjunto de hipóteses. Os autores pretendem com este modelo compreender o papel da imagem no comportamento consumidor (e.g. LGBT), estabelecendo, assim, cinco variáveis: imagem, qualidade, satisfação, regresso e recomendar.

É ponto concordante, por parte dos vários investigadores, o turista LGBT é um segmento de mercado bastante lucrativo e importante no desenvolvimento estratégico de um destino turístico (numa ótica regional ou local).

No que concerne à futura investigação, será pertinente alargar o estudo a diferentes tipos de destinos turísticos (e respetivos segmentos) e o aprofundamento das variáveis através de uma abordagem multidimensional. Paralelamente, procurar-se-á 
realizar a investigação num alargado período temporal da recolha dos dados e maior envolvimento dos stakeholders que (direta ou indiretamente) contribuem para a gestão e planeamento do destino turístico. Neste caso, optar-se-á por uma abordagem metodológica mista, adotando-se métodos de recolha de dados qualitativos e quantitativos com recurso a modelos de equações estruturais (i.e. imagem, compra, qualidade, satisfação, recomendar e revisitar) no segmento turístico LGBT.

\section{REFERÊNCIAS}

ANDERSSON, T. D.; GETZ, D. Stakeholder management strategies of festivals. In: Journal of Convention \& Event Tourism (v. 9, n. 3, p. 199-220). Taylor \& Francis Group, 2018.

AZEVEDO, M. S.; MARTINS, C. B.; PIZZINATTO, N. K.; FARAH, O. E. Segmentação no setor turístico: o turista LGBT de São Paulo. Revista de Administração da UFSM, 5 (3), p. 493-506, 2012.

BIGNE, J. E.; SANCHEZ, M. I.; SANCHEZ, J. Tourism image, evaluation variables and after purchase behaviour: inter-relationship. Tourism management, 22 (6), p. 607 616, 2001.

BEREZAN, O.; RAAB, C.; KRISHEN, A. S.; LOVE, C. Loyalty runs deeper than thread count: An exploratory study of gay guest preferences and hotelier perceptions. Journal of Travel \& Tourism Marketing, 32 (8), p. 1034-1050, 2015.

DOS SANTOS, S. E. M.; CHAVES, M. S.; PEDRON, C. D. An analysis of open-ended online reviews about bed and breakfast and inns in Portugal. Revista Brasileira de Pesquisa em Turismo, 8 (1), p. 99, 2014.

DUARTE, V. (2017) DM. Brazil. Acedido em: 10/12/2017. Disponível em: <https://www.dm.com.br/opiniao/2017/12/os-direitos-humanos-sao-para-todos.html>.

FERREIRA, J.; SOUSA, B. M.; GONÇALVES, F. Encouraging the subsistence artisan entrepreneurship in handicraft and creative contexts. Journal of Enterprising Communities: People and Places in the Global Economy, 2018

HOFFMANN, C.; DUARTE, R.; TRAVERSO, L. D.; BOBSIN, D. Turismo GayFriendly: Segmento de Demanda Latente/Gay-Friendly Tourism: Latent Demand Segment. Rosa dos Ventos -Turismo e Hospitalidade, 10 (4), 2018.

HUGHES, H. Holidays and homosexual identity. Tourism Managment, 18 (1), p. 3-7, 1997. 
HUGHES, H.; DEUTSCH, R. Holidays of older gay men: Age or sexual orientation as decisive factors? Tourism Management, 31, p. 454-463, 2010.

HUGHES, H. L. Lesbians as tourists: Poor relations of a poor relation. Tourism and Hospitality Research, 7 (1), p. 17-26, 2006.

ILGA International (s.d.), Maps - Sexual orientation laws. Acedido em: 10/12/2017. Disponível em: <http://ilga.org/maps-sexual-orientation-laws>.

ILGA Portugal (s.d.), Arraial Lisboa Pride. Acedido em: 30/11/2017. Disponível em: <http://ilga-portugal.pt/actividades/arraial-pride.php>.

INSTITUTO DE PESQUISAS E ESTUDOS DO TURISMO DO RJ, órgão da Associação dos Embaixadores de Turismo do RJ e a Fundação Cesgranrio (2017) VIAG turismo e diversidade. Acedido em: 10/12/2017. Disponível em: $<$ http://revistaviag.com.br/2017/02/01/pesquisa-mostra-o-perfil-do-turista-lgbt-do-riode-janeiro/>.

KAUHANEN, S. Think Pink in Tourism-A Study of LGBT+ Tourism, 2015.

LISBONBEACH (2017), Guia gay de Lisboa. Acedido em: 10/12/2017. Disponível em: <http://www.lisbonbeach.com/guia-gay-de-lisboa.html>.

LAGES, R.; SOUSA, B.; AZEVEDO, A. O posicionamento e a imagem em contextos de marketing de destinos turísticos: estudo de caso aplicado à cidade de Braga, European Journal of Applied Business Management, Special Issue, p. 15-32, 2018.

LUCENA, R.; JARVIS, N.; WEEDEN, C. A review of gay and lesbian parented families' travel motivations and destination choices: Gaps in research and future directions. Annals of Leisure Research, 18 (2), p. 272-289, 2015.

MACHADO, M. Turismo, medo e violência. Turismo e Sociedade, v. 6, n. 1, 2013.

MACHADO, A. F.; SOUSA, B. (2018) "Luxo Sustentável em Contextos de Hotelaria e Turismo: Do diferencial competitivo à preocupação com a responsabilidade social". International Journal of Marketing, Communication and New Media. Special Issue $4-$ Luxury Marketing, p. 28-56. Available at http://u3isjournal.isvouga.pt/index.php/ijmenm

MARCIAL, R. Identidad y representaciones del cuerpo en jóvenes gays de Guadalajara. La ventana. Revista de estudios de género, 3 (29), p. 7-31, 2009.

MISKOLCI, R. A Teoria Queer e a Sociologia: o desafio de uma analítica da normalização. Sociologias, 11 (21), p. 150-182, 2009. 
MONTERRUBIO, J. C. Identity and Sex: Concurent Aspects of Gay Tourism. Tourismos: An International Multidisciplinary. Journal of Tourism, 4 (2), p. 155-167, 2008.

NITSCHE, L. B. Por um turismo para as comunidades locais. Turismo e Sociedade, v. 6, n. 3, 2013.

OPÇÃO TURISMO (2016), Novo guia de Lisboa dirigido ao target LGBT. Acedido em: 10/12/2017. Disponível em: <http://opcaoturismo.pt/wp/novo-guia-de-lisboadirigido-ao-target-lgbt-2/>.

OSWIN, N. Decentering queer globalization: Diffusion and the 'global gay'. Environment and Planning D: society and space, 24 (5), p. 777-790, 2006.

OTERO PARADELA, A. B.; ALÉN GONZÁLEZ, M. E.; DOMÍNGUEZ VILA, T. Turismo LGTB. Una aproximación al caso de Galicia. Revista Galega de Economía, $23(1), 2014$.

PORTAL DEZANOVE (2013). O turismo gay como aposta para Portugal. Acedido em: 30/11/2017. Disponível em: <http://dezanove.blogs.sapo.pt/587351.html>.

PORTAL DEZANOVE (2017). O primeiro cruzeiro gay a começar em Lisboa. Acedido em: 30/11/2017. Disponível em: <http://dezanove.pt/o-primeiro-cruzeiro-gay-acomecar-em-1113136>.

PORTAL DEZANOVE (s.d). Portugal é o $16^{\circ}$ melhor país do mundo para turismo gay. Acedido em: 10/12/2017. Disponível em: <http://dezanove.pt/portugal-e-o-16o-melhorpais-do-mundo-733987?thread=1242147>.

PRITCHARD, A.; MORGAN, N. J.; SEDGELY, D.; KHAN, E.; JENKINS, A. Sexuality and holiday choices: conversations with gay and lesbian tourists. Leisure Studies, 19, p. 267- 282, 2000.

PRITCHARD, A.; MORGAN N. J.; SEDGELY D.; JENKINS, A. Reaching out to the gay tourist: opportunities and threats in an emerging market segment. Tourism Management, 19 (3), 273-282, 1998.

PÚBLICO 2012. A agência portuguesa para os viajantes gays. Acedido em: 10/12/2017. Disponível em: <http://fugas.publico.pt/Viagens/300172_a-agencia-portuguesa-para-osviajantes-gays $>$.

PUBLITURIS (2016). Porto vai ter guia LGBT em 2017. Acedido em: 10/12/2017. Disponível em: <https://www.publituris.pt/2016/10/28/porto-vai-ter-guia-lgbt-2017/>.

PÚBLICO (s.d.). Saga Escape. Acedido em: 30/11/2017. Disponível em: <www.lazer.publico.pt/outros/74211_saga-escape>. 
RUSSELL, P. The world gay travel market. Travel \& Tourism Analyst, (2), p. 37-58, 2001.

SANCHES, T. C.; MANCINI, L. A.; NASCIMENTO, M. A. N. Turismo GLS e o perfil do seu público consumidor na região norte do Paraná. Turismo - Visão e Ação, 13 (1), p. 81-95, 2011.

SANTOS, A. C. Entre a academia e o activismo: Sociologia, estudos queer e movimento LGBT em Portugal. Revista Crítica de Ciências Sociais, (76), p. 91-108, 2006.

SANTOS, A. C. Estudos queer: Identidades, contextos e acção colectiva. Revista Crítica de Ciências Sociais, (76), p. 3-15, 2006.

TOMAZZZONI, E. L.; SOUZA FIORE, V. DE; SOUZA, A. N. A parada do orgulho gay e suas contribuições para o desenvolvimento turístico social e humana da cidade de São Paulo. Revista TURYDES - Revista Turismo y Desarrollo Local, 7 (17), 2014.

WORLD TOURISM ORGANIZATION. (2012). Global Report on LGBT Tourism. Madrid: UNWTO.

WORLD TOURISM ORGANIZATION. (2014).UNWTO Annual Report 2014. Madrid: UNWTO.

HOLCOMB, B.; LUONGO, M. Gay tourism in the United States. Annals of Tourism Research, 23 (3), p. 711-713, 1996.

MONTERRUBIO, J. C. Identity and Sex: Concurent Aspects of Gay Tourism. Tourismos: An International Multidisciplinary. Journal of Tourism, 4 (2), p. 155-167, 2008.

KIRBY, S.; HAY, I. (Hetero) sexing space: gay men and "straight" space in Adelaide, South Australia. The Professional Geographer, 49 (3), p. 295-305, 1997.

PRITCHARD, A.; MORGAN, N. J.; SEDGELY, D.; JENKINS, A. Reaching out to the gay tourist: opportunities and threats in an emerging market segment. Tourism management, 19 (3), p. 273-282, 1998.

RODRIGUES, C.; MONIZ, A.; TIAGO, F. (2018). Turismo gay: Estão preparados?. Revista Turismo \& Desenvolvimento, 1 (27/28), 2255-2264.

SOUSA, B. Dynamic differentiation and the creative process in tourism management destinations. Revista Brasileira de Pesquisa em Turismo - RBTur, 10 (1), p. 3-17, jan./abr., São Paulo, 2016, e-ISSN 1982-6125. 
SOUSA, B.; SIMÕES, C. (2014) Comportamento e perfil do consumidor de turismo de nichos. Tékhne-Revista de Estudos Politécnicos, (14), p. 137-146, 2010. ISSN: 16459911.

Recebido em: 15-05-2018.

Aprovado em: 14-06-2018.

Versão finalizada em: 28-12-2018. 